\title{
A multiplicidade da secularização: a sociologia da religião na era da globalização
}

Carlos Eduardo Sell'

\section{Resumo}

A teoria weberiana da secularização é atualmente criticada por reproduzir pressupostos teleológicos oriundos das teorias da modernização. Defrontando-se com essa crítica, este artigo retoma a tese da unidade e variação desenvolvida por Shmuel Eisenstadt e, a partir de tais pressupostos, discute as possibilidades de atualização do conceito de secularização diante do cenário da globalização e da multiplicidade da modernidade. Após demonstrar que em Max Weber o tema já é tratado de forma multidimensional (histórica e estrutural), o artigo busca sistematizar o debate sobre a secularização no campo da sociologia da religião. Em seguida, examinam-se criticamente três modos distintos de apreensão das variedades da secularização: I) multiplicidade de vias de secularização, 2) múltiplos secularismos e 3) múltiplas secularidades. O artigo advoga pela fecundidade e atualidade da teoria da secularização para determinar não só a natureza e a diversidade do religioso em condições modernas mas também para determinar o moderno na sua relação com o religioso.

Palauras-chave: Max Weber. Religião. Secularização. Múltiplas Modernidades. Secularismo. Laicidade.

\section{Introdução}

No pensamento de Max Weber, a religião, mais do que objeto de uma sociologia aplicada, é o locus metodológico estratégico para se pensar a condiçáo moderna. Contudo, tal centralidade reflete-se de forma desigual nos desdobramentos da sociologia weberiana contemporânea. A teoria das modernidades múltiplas de orientação culturalista de Shmuel Eisenstadt (2001) deu bastante destaque à questáo; mas, na sua vertente estruturalista - representada

Doutor em Sociologia Política e professor do Programa de Pós-Graduação em Sociologia Política da UFSC (Universidade Federal de Santa Catarina). 
hoje por Thomas Schwinn (2013), somente agora esse tema começa a merecer uma atenção mais detalhada ${ }^{2}$. No debate sobre a natureza da modernidade no Brasil, a situação não é muito distinta, e a despeito de algumas incursôes importantes, como em Ortiz (2006) e Tavolaro (2005) -, a variável religião vem sendo pouco explorada parar entender as profundas transformaçóes sociais em curso.

Levar em conta o papel da religiáo no contexto social não é uma exigência que decorre apenas de razóes teórico-imanentes, mas um clamor que brota da realidade. Como pensar a condição da modernidade no Brasil sem considerar a imensa transformação de seu perfil religioso que, de majoritariamente católico (em 1872 eles eram 99\% da população), conta agora com uma significativa comunidade evangélica $(22,2 \%)$, reduzindo-se os católicos a 64\%? Tal dado impóe a necessidade de um diálogo entre teoria sociológica e sociologia da religião. No entanto, no Brasil, tal área tem reforçado cada vez mais suas características endógenas e a principal categoria macrossociológica a pensar os vínculos entre modernidade e religiâo - a secularização - vem perdendo centralidade nas discussóes.

Nos anos 1990, o tema ainda foi o foco de uma instrutiva controvérsia. De um lado, Antônio Flávio Pierucci (1997a, 1997b, 1999) centrou seu fogo contra o que denominou de teóricos da "volta do sagrado", estudiosos que, segundo ele, estariam a ver no dinamismo da esfera religiosa brasileira uma negação das teses da secularização (PIERUCCI, 1998). De outro lado, tais estudiosos negaram-se a assumir a condição revisionista a eles atribuída (NEGRÃO, 2005), além de criticarem os vínculos estreitos entre a concepção weberiana da secularização e a sociologia da modernização (MONTERO, 1999, 2003a, 2003b; VELHO, 1998). Apesar da defesa da centralidade da categoria (MARIANO, 2012), a crítica ao caráter teleológico do paradigma da secularização não foi ainda suficiente respondida e, na prática, o debate sobre a secularização, ainda que não totalmente ausente, vem sendo sutilmente sobrepujado por novas perspectivas (como as da laicidade e do secularismo), estreitando-se fortemente na direção do político. Impulsionados pelos crescentes conflitos entre grupos religiosos e seculares na esfera pública (POMPA,

2 Para a distinção entre uma versão culturalista e outra institucionalista da sociologia neoweberiana, conferir Sell (20/4). 
2012), que se acentuaram dramaticamente nos últimos anos, os pesquisadores brasileiros rapidamente voltaram suas lentes para o acompanhamento etnográfico das disputas em curso e deixaram em segundo plano o debate sobre a secularização. O fato é que, de Weber, a discussão sociológica foi sendo quase inadvertidamente remetida aos braços de Durkheim e sua luta por uma moral laica (WEISS, 2013). Atualmente, é cada vez mais a dinâmica da concorrência (intra) religiosa que vem despertando o interesse dos analistas ${ }^{3}$, deslocando a discussão do eixo "religiáo/sociedade" para a polaridade "religiáo/política".

Diante desse cenário, o clamor levantado por Pierucci (1998) bem poderia ser novamente levantado: de volta à secularização. Se entendermos, provisoriamente, secularizaçáo como um conceito que conserva um nexo interno religião e modernidade (DUTRA, 2016), tal categoria é fundamental para o desenho uma sociologia comparativa capaz de determinar os elementos de unicidade e pluralidade da realidade contemporânea. Entretanto, caso queira cumprir tal desiderato, a teoria da secularização precisa assumir e responder aos desafios que lhe são colocados por uma realidade social cada vez mais globalizada e por uma sociologia de orientação cosmopolita, desvinculando-se dos pressupostos da teoria da modernizaçáo. Não se trata de simplesmente dispensar o conceito (MONTERO, 2009, p. 10), mas de se perguntar de que modo ele pode ser reconfigurado diante desse novo cenário. Ancorando-se na dualidade unicidade/variedade, proposta por Eisenstad, este artigo: 1) reexamina a concepção da secularização em Weber, 2) sistematiza o estado da arte sobre o tema da sociologia da religião contemporânea e, ao final, 3) discute criticamente algumas tentativas de sua atualização.

\section{A secularização em Weber: entre o histórico e o estrutural}

Exposições históricas sobre o vocábulo secularização (MARRAMAO, 1999), em regra, seguem o mesmo padrão: começam pela genealogia do conceito e examinam, a seguir, sua introdução no léxico das ciências humanas. Essa trajetória, contudo, corre o sério risco de ser lida de forma linear, sem maior atenção para as reconfigurações e mutações que o conceito sofre

3 No Brasil, balanços gerais da esfera religiosa no Brasil costumam acompanhar os dados do censo. Assim, se em relação aos dados de 2000, a secularização ainda foi o centro do debate (TEIXEIRA; MENEZES, 2006), no levantamento posterior (TEIXEIRA; MENEZES, 20I3) a concorrência assumiu a dianteira nas análises. 
ao longo dessa trajetória. Evitando essa armadilha, Herman Lübbe (1965) recorda que o tema da secularização é alvo de disputa política e que seu conteúdo é determinado em função de diferentes necessidades teóricas e pragmáticas: ele não permanece inalterado e sofre reconfigurações semânticas a depender dos interesses em jogo. Essa indicação nos fornece uma preciosa pista para caracterizar dois momentos fundamentais da inserção desse conceito no âmbito da sociologia, que são o final do século XIX (momento de fundação da sociologia) e o cenário do pós-segunda-guerra do século passado (momento de autonomização da sociologia da religião como área especializada do saber sociológico). Fundamental é prestar atenção às continuidades e descontinuidades que a noção sofre em cada uma dessas passagens, pois enquanto no primeiro momento o conceito de secularização é utilizado primordialmente como instrumento pelo qual a sociologia pensa o moderno; no pós-guerra a secularização torna-se instrumento para pensar a religião (SELL, 2015).

Quando nos reportamos ao momento de gênese da sociologia, é praticamente consenso entre os intérpretes que Max Weber é a principal figura responsável tanto pela a) introdução desse léxico nas ciências humanas quanto b) pela sua fixação como instrumento teórico central para a compreensão da condição moderna. Menos consensual, contudo, é o modo pelo qual Max Weber realiza essa introdução. Para Pierucci (1998), por exemplo, Weber apenas reproduz as premissas jurídicas contidas na história do conceito. Já Borutta (2010), em direção contrária, sustenta que o conceito está fortemente impregnado da cosmovisão anticatólica da intelectualidade liberal protestante, dominante no meio acadêmico da Alemanha Guilhermina. A maioria dos historiadores, contudo, enfatiza o fato de que, em Weber, o conceito é esvaziado de suas conotaçóes ideológicas e neutralizado para fins de análise descritiva dos processos sociais ${ }^{4}$.

Se, quanto a este ponto, não reina acordo, bem mais polêmico ainda é o assunto quando se trata de examinar como o legado weberiano foi relido e tornou-se a fonte matricial das mais diversas teorias da secularização que vão se desenvolver no interior de uma área específica da investigação social:

Nas palauras de Lübbe (p.68): "Weber utiliza este conceito, como mais tarde o farão os sociólogos americanos antes citados [por Lübbe], com uma completa indiferença valorativa e como uma categoria científica operativa". 
a sociologia da religião. De fato, o que, no decorrer do pós-guerra, será denominado "teoria da secularização" não é uma criação direta de Max Weber que, por sinal, em sua Religionsystematik (como ele também chamou o capítulo de sociologia da religiáo de Economia e Sociedade, escrito por volta de 1913) emprega o termo apenas duas vezes e, mesmo assim, de forma bastante secundária. $\mathrm{O}$ termo também não está presente em nenhum dos textos metodológicos centrais de sua sociologia comparada das religióes, como sua Observaçâo preliminar (Vorbemerkung), a Introdução (Einführung) e a Consideração Intermediária (Zwischenbetrachtung), entre outros, e está longe da centralidade que ocupam as categorias racionalidade e desencantamento do mundo em sua sociologia global. Uma teoria da secularização nos moldes de uma sociologia da religião tematicamente restrita apenas pode ser identificada neste autor por meio de um procedimento que é essencialmente reconstrutivo, advindo daí a inevitável pergunta: o que significa, em Weber, a ideia de secularização?

A reconstrução a posteriori de uma teoria weberiana da secularizaçáo segue basicamente dois procedimentos: o filológico (indutivo) e o sistemático (dedutivo). Pelo primeiro, inventaria-se o uso do termo secularização e procura-se, a partir daí, derivar o sentido da ideia de secularização. No procedimento sistemático, por sua vez, a recorrência do termo não é ignorada, mas é do conjunto da obra e de suas intenções que uma teoria da secularização é extraída.

Do ponto de vista filológico, Pierucci (1998), de forma modelar, inventariou cuidadosamente as passagens em que Weber se utiliza do termo "secularização". Tal levantamento fê-lo constatar que a noção é empregada a maior parte das vezes em sua sociologia do direito, razáo pela qual ele sustenta que estaria aí o núcleo duro do mesmo. Como argumento adicional, sugere o intérprete, Weber apenas preserva a raiz etimológica do conceito, que é de natureza jurídica. Disso, conclui que:

É tamanha a desproporção entre a quantidade concentrada de ocasiões em que Säkularisation/ Säkularisierung/ säkularisiert/ säkularisierend aparecem no ensaio de sociologia do direito e, de outro lado, suas esporádicas e rarefeitas aparições noutros textos e contextos teóricos da obra weberiana, que tudo se passa como se aí se expressasse uma tácita intenção de indicar que o objeto designado é, no seu cerne, naquilo que realmente conta, jurídico-político. Em minha pesquisa pude constatar empiricamente nos escritos de Weber uma dominância do sentido original do nome, antiguidade de sentido que não se apaga, não se retrai, está sempre ali, sempre despontando. (PIERUCCI, 1998, p. 63). 
Todavia, a mera predominância (quantitativa) da passagem em certo contexto da obra de Weber não nos permite, por si só, derivar daí o significado fundante (qualitativo) do conceito. Martin Riesebrodt (2001, p. 116), outro autor a examinar o termo, chega à conclusão contrária e prefere derivar o conteúdo exatamente dos escritos em que Weber a menciona fora da sociologia do direito, a começar por seu artigo sobre As seitas americanas e o espirito do capitalismo (1906), no qual, por sinal, o conteúdo semântico do conceito é muito mais claro. Realmente, se observarmos o modo como Weber utiliza o conceito de secularização neste escrito, veremos que ele se aproxima da forma como a noção é empregada nos modernos estudos da sociologia da religião. Nas palavras de Weber, "[...] um exame detalhado revela o constante progresso do processo característico de 'secularização' a que, nos tempos modernos, sucumbem todos os fenômenos que se originaram em concepções religiosas" (WEBER, 1988, p. 212, itálico meu). E, na sequência, mostrando as raízes religiosas do associativismo americano, temos uma nova sentença, com o seguinte teor: "[...] estamos interessados no fato de que a moderna posição dos clubes e sociedades seculares, com recrutamento por eleição, é em grande parte um produto do processo de secularização" (WEBER, 1988, p. 217). Mas, nesta passagem, explica Monod (2002, p. 106), diferente da anterior, Weber emprega o termo secularização como transferência e não como ruptura: “[...] o interesse de Weber se dirige muito menos ao declínio das concepções religiosas que sobre a continuidade de funçâo" dos clubes em relação às seitas.

Logo, estudos que seguem o método léxicográfico não são conclusivos e, dado que Weber nunca definiu explicitamente e indubitavelmente o significado de secularização, todos os inventários do termo acabam privilegiando algum uso do mesmo ou acabam tendo de apelar para alguma unidade de análise mais abrangente da qual acabam derivando seu significado. $\mathrm{O}$ procedimento indutivo transfigura-se, afinal, em método dedutivo. $\mathrm{O}$ que podemos esperar, entâo, do método sistemático?

Esse procedimento metodológico sustenta que uma teoria weberiana da secularização não se restringe ao inventário do conceito, e ainda que não esteja explicitamente formulada, pode ser deduzida de suas análises sócio-históricas de longo alcance, a começar pela sua descrição da transição entre conduta puritana e ethos profissional. O problema é que muitos destes estudos acabam nivelando as diferenças entre os conceitos centrais da sociologia weberiana, 
em especial as noções de racionalização (SELL, 2013), desencantamento do mundo (PIERUCCI, 2003) e secularização, como se cada um dos termos, em Weber, fosse sinônimo.

Tanto o método filológico quanto o método sistemático possuem limitaçôes. $\mathrm{O}$ primeiro por restringir a discussão ao termo isoladamente considerado, encurtando o alcance da discussão; $\mathrm{O}$ segundo, por alargar de tal modo seu sentido que ele acaba ficando indeterminado.

Fugindo das aporias a que levam os dois procedimentos descritos acima, Wolfgang Schluchter (1988, p. 506-534) nos apresenta uma versão de secularização que, sem deixar de partir do texto de Weber, náo se restringe ao procedimento de determinação do conteúdo do conceito isoladamente e, ao mesmo tempo, não descuida da dimensão sistemática da noção (ou seja, de sua relação com o conjunto da obra). A versão da teoria da secularização defendida por ele toma como ponto de partida a teoria da diferenciação social elaborada por Weber em sua Consideração Intermediária (Zwischenbetrachtung). Ao retomar este escrito, Schluchter não se apoia na dimensão histórico-diacrônica do conceito, mas em sua dimensão histórico-estrutural. Não se trata de privilegiar a descrição dos processos de gênese da modernidade (a partir da religiáo), nem dos influxos históricos do moderno sobre o caráter da religião, mas sim de deslocar nossa atenção para o status ou lugar do religioso no cenário atual da modernidade diferenciada segundo distintas esferas de valor e ordens de vida. Prosseguindo nessa direção, Schwinn (2013) descreve como, nos moldes weberianos, as relaçóes entre religião e modernidade são pensadas a partir da ideia de conflito. Ao descrever a legalidade intrínseca das ordens de vida e esferas de valor, Weber demonstra como a religião encontra-se em uma relação de tensão [Spannung] com as ordens econômica e política e, ao mesmo tempo, de competição com as esferas estética, erótica e intelectual. Nesse ponto, um retorno ao escrito weberiano será especialmente útil.

Que é de tensão que se trata, é o próprio Weber que nos sinaliza, ao afirmar, logo no início do texto, que seu objetivo consiste em "examinar em detalhe as tensóes existentes entre a religião e o mundo" (WEBER, 1989, p. $211)^{5}$. Ele tem consciência de que "[...] a religião da fraternidade sempre se chocou com as ordens e valores deste mundo e, quanto mais coerentemente

5 Trecho de Zwischenbetrachtung. Die Wirtschaftsethik der Weltreligionen. Konfuzianismus und Puritanismus (Schriften 1915-1920) (WEBER, 1989). De agora em diante, referida da seguinte forma: Zwischenbetrachtung, MWG I/I9. 
suas exigências foram levadas à prática, tanto mais agudo foi o choque" (WEBER, 1989, p. 214). Para ele, "a tensão entre a religião fraternal e o mundo foi mais evidente na esfera econômica" (WEBER, 1989, p. 214), mas sem esquecer que "[...] as religiōes que sustentaram uma ética da salvação fraternal coerente são em tensão igualmente aguda em relação às ordens políticas do mundo" (WEBER, 1989, p. 215). Weber conclui que "[...] a ética religiosa da fraternidade situa-se em tensão dinâmica com qualquer comportamento consciente-racional que siga suas próprias leis" (WEBER, 1989, p. 222). Tal tensão, por sinal, não existe apenas na esfera político-econômica: " [...] em proporções não menores, essa tensão também ocorre entre a ética religiosa e as forças de vida 'deste mundo' cujo caráter é essencialmente não-racional ou basicamente anti-racional" (WEBER, 1989, p. 222). O que temos aqui, portanto, é um segundo complexo de instituiçóes, cuja lógica de tensão com a religião é de outra natureza: trata-se de uma relação marcada pela competição. Ao referir-se à esfera artística e à esfera erótica, o que Weber demonstra é a "afinidade psicológica" (WEBER, 1989, p. 224) que ambas possuem com a experiência religiosa. É justamente esse caráter que faz com que, à medida que se tornem autônomas, elas colidam com as pretensóes religiosas. No entanto, é em relação à esfera intelectual o que o locus atribuído por Max Weber à religiâo em condiçóes modernas fica mais transparente:

A tensão entre religião e o conhecimento intelectual destaca-se com clareza sempre que o conhecimento racional, empírico, funcionou coerentemente através do desencantamento do mundo e sua transformação num mecanismo causal. A ciência encontra, então, as pretensões do postulado ético de que o mundo é um cosmo ordenado por Deus e, portanto, significativo e eticamente orientado [...]. Todo aumento do racionalismo na ciência empírica leva a religião, cada vez, do reino racional para o irracional: mas somente hoje a religião torna se o poder supra-humano irracional ou antirracional. (WEBER, 1989, p. 227).

Nessa passagem de Weber, dois processos ficam patentemente claros. Por um lado, 1) a religião perde seu papel central como força que define o sentido do mundo; um processo que, por sua vez, 2) altera a natureza da esfera religiosa que se retira para o reino do irracional ou antirracional.

Para Weber, o deslocamento da esfera religiosa do centro para a periferia da ordem social é um elemento constitutivo da vida moderna e ocidental, vale também mencionar, da primeira modernidade (princípio de unidade). Porém, isso não significa que a análise weberiana náo contemple o fenômeno 
sob óticas diversas. $\mathrm{O}$ tema da secularização vem articulado analiticamente de modo múltiplo, e pode ser entendido tanto como 1) processo histórico (versão dinâmica) proporcionado pela própria religiáo (fator interno) quanto como 2) resultado de outras variáveis sociais da modernidade que afetam a esfera religiosa (fator externo). Por este segundo ângulo, a secularização é descrita como diferenciação social, condição que coloca a religião em tensão constante com as demais esferas culturais, ordens sociais e modos de vida autônomos da modernidade. Em suma, em Weber o tema de secularização é descrito tanto no registro histórico/diacrônico quanto estrutural/sincrônico. Em ambos os casos, trata-se sempre da reflexão sobre a relação entre religião e modernidade, seja em relação ao problema da gênese, seja em relação ao problema da especificidade do mundo moderno.

\section{A secularização na sociologia da religião: entre o declínio e a individualização}

Embora a análise weberiana da relação religião/modernidade comporte múltiplas perspectivas, seu legado foi ambíguo e foi a filosofia, e não a sociologia, a que melhor explorou a dimensão mais ampla (histórica) da tese da secularização. O célebre debate entre Karl Löwith (1949) e Hans Blumenberg (1996 [1966]) evidencia duas formas distintas de entender o caráter da modernidade, a depender do papel de suas raízes religiosas: como transferência ou como ruptura. $\mathrm{O}$ que estava em jogo, como dirá este segundo, era a própria legitimidade dos tempos modernos. Quanto à sociologia, o tema da secularização vai encontrar abrigo na área cada vez compartimentalizada da pesquisa setorial sobre religião. Assim, enquanto na filosofia a religião é pensada como veículo para a definição do moderno, na sociologia, por sua vez, é o moderno que se torna o veículo para a definição do religioso. Qual é, nesta segunda área de estudos, o estado da arte desse debate?

Em Pierucci, o debate sobre a secularização ainda é apresentado em termos fortemente dualistas: secularização x volta do sagrado, afirmação e negação. Atualmente, esse cenário está bastante mudado. Com o lento emergir e a consolidação de um novo paradigma nos estudos sociológicos sobre religiáo, a controvérsia sobre a secularização sofreu importantes deslocamentos. A chamada teoria do mercado religioso tornou-se a principal algoz das vertentes da 
secularização e, centrando-se apenas no pluralismo concorrencial, decretou essa querela como sepultada (STARK, 1999). Do outro lado, os dois principais paradigmas da sociologia da religiáo (a teoria da secularização e a teoria da individualização ${ }^{6}$ ), apesar das suas diferenças, ainda mantêm o problema no centro do debate, embora advoguem entendimentos diferentes sobre o fenômeno: para o primeiro, secularização é sinônimo de perda de relevância do religioso (versão ortodoxa) e, pelos menos para uma parte dos teóricos do segundo paradigma, a secularizaçáo pode ser definida alternativamente como a privatização da crença (versão heterodoxa). Portanto, ainda que defensores e críticos da secularização mantenham entre si uma relação de disputa teórica, as divergências tornaram-se menos antagônicas e é preciso considerar, além dos distanciamentos, as aproximaçóes e convergências entre essas duas grandes narrativas $^{7}$ da secularização (LEHMANN, 2004; ZEPEDA, 2010). É a partir desta estratégia que pretendo caracterizar as principais tendências que podem ser vislumbradas nesta já longa controvérsia.

Para seus críticos mais contumazes, a tese da secularização não passa de mito ou ideologia (HADDEN, 1987), enquanto seus partidários insistem que não se trata de uma teoria, mas de um paradigma (TSCHANNEN, 1991), ou ainda, de uma família de teorias (GORSKI, 2000). Tal diversidade, contudo, não impediu que seus defensores se esforçassem para definir até uma plataforma comum de conceitos: Bryan Wilson (1966, 1982, 1985), por exemplo, propõe diferenciação, racionalização e societalização; Tschannen (1991) diferenciação, racionalização e mundanização; e Dobbelaere (2002) divide a secularização em diferentes níveis: macro/societário, meso/organizacional, micro/ individual. No entanto, tais exemplos já bastam para mostrar que, a despeito do esforço realizado por seus teóricos para explicitar suas convergências, tentativas de fixar um núcleo compartilhado de conceitos, este ainda não foi alcançado. Uma via alternativa seria tentar definir o paradigma da secularização a partir de sua proposição empírica básica, como o faz, por exemplo, Peter Berger (1967, p. 119): “[...] a secularização é o processo pelo qual setores da sociedade e da cultura são subtraídos à dominação das instituições e símbolos

6 Para essa divisão em três vertentes, parti da sistematização de Pickel (2011).

7 Acompanhando Koschorke (2013, p. 237-260), emprego aqui o termo narrativa em sentido mais amplo que teoria, modelo ou até mesmo paradigma -, remetendo-me à noção de "metanarrativa" já empregada por Lyotard. 
religiosos". Entretanto, essa formulação nos diz muito pouco sobre como o paradigma da secularização (e seus diversos autores) sustenta teoricamente tal enunciado, ou seja, ela permanece no nível descritivo e não toca na dimensáo especificamente causal-explicativa do problema.

Inspirando-me na análise de Mouzelis (2012), penso que esta pergunta pode ser respondida se diferenciarmos novamente duas dimensôes distintas no que diz respeito ao aspecto propriamente teórico (causal-explicativo) das diversas correntes ou autores que tratam da secularização: sua dimensão externa e sua dimensão interna. $\mathrm{O}$ que chamo de dimensão externa refere-se à variável societária (ou independente) adotada por estas teorias, ou seja, em regra, sua própria concepção de modernidade.

No tocante ao primeiro aspecto, embora muitos teóricos (NORRIS; INGLEHART, 2004; POLLACK, 2012 et alli) prefiram apostar nos fatores da modernização como causa da secularização (industrialização, urbanização, escolarização etc.); para a maioria dos estudiosos, contudo, do paradigma da secularização, é a categoria da diferenciação que constitui o aspecto macrossocial central.

E, apesar de, em regra, adotarem a tese da diferenciação como eixo externo de suas teorias, existem diferenças importantes no modo como os teóricos da secularização descrevem esse conceito. Para alguns, tal diferenciação tem um caráter funcional, enquanto outros se limitam a adotar a expressão apenas com seu adjetivo social, dispensando o aspecto funcionalista da noção (interdependência de parte e totalidade social). Existe, também, outra diferença importante. Enquanto determinados teóricos adotam um viés estritamente sociológico, outros entendem essa diferenciação do ponto de vista politológico. No primeiro caso, a perda de centralidade da esfera religiosa se deve exclusivamente à sua transformação em esfera autônoma da vida social e, de forma correlata, ao fato de que as esferas autonomizadas passem a operar com lógicas intrínsecas que são indiferentes ou mesmo opostas ao aspecto religioso. No segundo caso, tal processo náo pode ser pensado de forma desarticulada de variáveis políticas, em especial a laicização do Estado, ou seja, o sistema político é considerado o agente promotor desse processo. A primeira variaçáa, portanto, é sociocêntrica, enquanto a segunda variante é estadocêntrica e, neste segundo caso, somente um poder político capaz de se autolegitimar, sem 
referência a fundamentos religiosos, abre caminho para a autonomização das esferas sociais. Para uma terceira posição, por sua vez, a secularização não é o efeito produzido pela transformação da religião em esfera específica da vida social, mas a própria separação em si mesma. Diferenciação e secularização são consideradas, portanto, como sinônimas (YAMANE, 1997; LUHMANN, 2002; CASANOVA, 1994).

Em se tratando da dimensáo interna (ou especificamente religiosa), o cenário é ainda mais variado. Teóricos da secularização recorrem a diversos conceitos para tipificar a perda de relevância da religião na vida social, como bem descreve a lista elaborada por Dobbelaere: racionalização, mundanização, autonomização, privatização, generalização, pluralização, declínio da prática religiosa, colapso da visão religiosa de mundo, descrença, cientifização, sociologização etc. Esse dado é importante pelo fato de que, na visão dos seus partidários, o paradigma da secularizaçáo não pode ser considerado linear e determinista, já que ele se caracteriza justamente pelo esforço de pensar a condiçáo do religioso na modernidade de maneira multidimensional.

Passemos, agora, à posição contrária. A gênese e a crítica das teorias da secularização são fenômenos praticamente concomitantes; afinal, no mesmo período em que Peter Berger (1967) e Bryan Wilson (1966), entre outros (como Steve Bruce em 1966; 1992, 2002, 2011a e 2011b), consolidavam a tese da perda de relevância da religião, Thomas Luckmann (1967), por outro lado, contestava esta visão e proclamava que, longe de levar ao desaparecimento ou declínio, a modernidade provocava, ao contrário, a mutação do religioso. Para ele, a religião seria uma constante antropológica e na modernidade o desejo da transcendência foi rearticulado em novas roupagens: a religião tornou-se invisível, isto é, espraiou-se para além das organizaçóes religiosas formais. Luckmann rejeita o socientrismo de Durkheim (religião = sociedade) e radica o religioso na natureza humana (essencialismo antropológico), ainda que conserve do autor francês a hipótese da necessidade funcional da religiáo. Luckmann pode ser considerado a matriz das teorias que, posteriormente, irão pensar o fenômeno da secularização de forma alternativa, ou seja, que operam com a equaçáo secularizaçáo = privatizaçáo do religioso ou, posto de outra forma, que advogam a passagem de formas tradicionais/institucionais de religiosidade para uma "religiosidade implícita/invisível". 
Todavia, antes de demonstrar esse ponto, é precisar acentuar que, comparados com os teóricos que se reconhecem como partidários do paradigma weberiano da secularização, nas suas versóes contrárias não predomina a tentativa de fixação de parâmetros formais ou metodológicos comuns. Tais tendências são muito menos articuladas e sua referência comum é basicamente negativa, pois seus proponentes se definem, em geral, pela oposição à narrativa convencional que identifica secularização como perda de relevância da religião. Embora muita tinta já tenha sido gasta na tentativa de unificar as narrativas ortodoxas da secularização, menos esforço tem sido feito no sentido de reconhecer os elementos de unidade teórico-formal de suas abordagens contrárias. Minha proposta é classificar as críticas à narrativa tradicional da secularização em duas grandes variantes: a) teorias da reversão e b) teorias da mutação.

Teorias da reversão apostam basicamente na identificação de processos sociais que desmentem empiricamente os prognósticos do paradigma da secularização. De um lado, estariam processos intra-religiosos como a crescimento pentecostal, a vitalidade do islamismo e a proliferaçáo de novos movimentos religiosos etc.. Em adição a esse aspecto, alega-se também que a própria modernidade alterou-se em sua natureza e que, portanto, tais processos extra-religiosos também se refletem na revitalização da crença. $\mathrm{O}$ raciocínio é que a pós-modernidade (MARTELLI, 1995), segunda ou alta modernidade (ou qualquer outro nome que se queira adotar a condição social atual), implica, como consequência (MARTEL) tendências de "dessecularização" (BERGER, 1999) ou "pós-secularização" (ACQUAVIVA; STELLA; BERZANO, 1990). Termos como "volta dos deuses" (RIESEBRODT, 2000), "retorno do sagrado" (BELL, 1977), "des-privatização do religioso" (CASANOVA, 1994) ou até mesmo "vingança de Deus" (KEPEL, 1991), entre outros, procuram, entáo, descrever este novo estado de coisas.

Diversamente, teorias da mutação apostam em outra leitura: a versão weberiana da secularização está equivocada não porque foi desmentida pela (inesperada) dinâmica dos fatos, mas porque eles foram interpretados de forma incorreta. Seguindo o caminho já aberto por Luckmann, afirma-se estar em curso um processo de adaptaçấo das formas de crer e praticar a religiáo a partir de possibilidades criadas pela própria modernidade. Seguindo aqui uma sugestão dada por Gorski (2000), tal modelo poderia ser ainda diferenciado segundo duas linhas de argumentação que separam, de um lado, a transformação 
do religioso (surgimento de uma religiáo difusa) e, de outro, a privatização das crenças e práticas religiosas. Creio, contudo, que essa distinção acaba por ser redundante, pois a principal transformação da qual se trata é justamente esse processo de subjetivação do crer. Mais importante é prestar atençáo ao fato de que, para determinado grupo de críticos da tese ortodoxa, a privatização da crença assume o posto de teoria alternativa da secularização (opondo-se a ela), mas para um segundo grupo dele a privatização do religioso pode ser lida com uma conceituação alternativa de secularização, quer dizer, como um modo distinto de definir esse processo. Portanto, na sua versão ortodoxa (predominante) a privatização é pensada como fenômeno causado pela secularização, enquanto na versão heterodoxa (minoritária) ele é interpretado como fenômeno equivalente. Trata-se, neste caso, de uma interessante reapropriação e resemantização do conteúdo desse conceito. Não devemos esquecer, é claro, que nem todos os teóricos do paradigma da privatização do religioso adotam e reformulam o conteúdo do conceito de secularização desta forma (tornando-os praticamente sinônimos), mas este é o caso de uma importante parcela deles, como ilustram, entre outros, os trabalhos de Hérvieu-Léger (1986, 1989, 1999), Charles Taylor (2007) e Hans Joas (2012).

Ao longo de seu desenvolvimento como área aplicada de investigação, a sociologia da religiáo revelou-se como um campo polarizado entre duas grandes narrativas que disputam a validade da matriz weberiana, bem como a interpretação sobre o lugar e o peso do religioso em condiçôes modernas. Por outro lado e, apesar das suas diferenças, cada uma das posiçôes também evidencia que na sociologia a questão da secularização foi reduzida ao tema da natureza da religiáo em condiçóes modernas, deixando em segundo plano o tema da natureza da modernidade na sua relação com o religioso. De teoria do moderno (a partir do religioso), a secularização transmutou-se em teoria do religioso (a partir do moderno).

\section{A secularização no cenário global: de regra à exceção ou da uniformidade à multiplicidade?}

Além da premissa acima identificada, o debate sobre modernidade e religião parece esconder ainda outro consenso: seja como perda de relevância, seja como privatização, na transição do tradicional para o moderno, as sociedades 
confluem para o mesmo destino: a secularização. Com o giro cosmopolita hoje vigente nas ciências sociais, tal premissa foi posta sob a suspeita do eurocentrismo: longe de regra, a secularização não passaria, pois, de uma excepcionalidade. Sob esse signo, até mesmo um teórico de incontestável prestígio como Jürgen Habermas descreveu essa nova situação como "pós-secular", entendo-a como uma nova consciência das sociedades seculares:

O que tentamos aqui, adotando o ponto de vista do observador sociológico, é responder a pergunta do porque podemos chamar de "pós-seculares" sociedades amplamente secularizadas. Nestas sociedades, a religião mantém uma relevância pública, ao mesmo tempo em que vai perdendo terreno a certeza secularista de que no curso de uma modernização acelerada, a religião desaparecerá em escala mundial. (HABERMAS, 2007, p. 69).

Tal indagação coloca a controvérsia da secularização sob um novo prisma e põe em questão a seguinte pergunta: afinal, a secularização é um fenômeno necessário ou contingente? Dito de outro modo: secularização e modernidade são fenômenos intrinsecamente relacionados, ou a secularização é apenas de uma particularidade histórica da primeira modernidade (europeia)? Posto nestes termos, o debate sobre a secularização desloca-se do eixo temporal tradição/modernidade/pós-modernidade, no qual tem se movido até agora, para contemplar uma nova dimensão analítica: uma nova díade entre em cena e diz respeito ao nacional/global, exigindo um descentramento da análise. Meu pressuposto é que essa nova perspectiva não implica nem a defesa incondicional, nem a rejeição in totum da teoria secularização (em suas diferentes versóes). Na trilha do trabalho de Eisenstadt (2001), uma teoria que assuma o pressuposto de que a secularização é uma condição intrínseca da modernidade está posta diante do problema de discriminar tantos os elementos de unidade quanto de diferença ou variedade deste fenômeno. Perseguindo esta pista de trabalho, este último tópico tipifica e avalia teoricamente três tentativas que, assumindo esse global turn, buscam repensar a temática da secularização sob a ótica de suas variaçóes: 1) a histórico-processualista; 2) a político-construtivista e 3) sociológico-institucionalista.

\section{I As múltiplas vias da secularização}

No debate sobre a secularização, Europa e Estados Unidos alternam o posto de regra ou de exceção (DEMERATH III, 1988; TORPEY, 2010). 
De qual caso devemos partir para confirmar ou refutar o processo de secularização: do velho ou do novo mundo? A concentração desse debate nas sociedades do quadrante norte do planeta já revela sua limitação geográfica e fragiliza ainda mais a tese da universalidade da secularização. Até agora, as versôes heterodoxas da secularização, apesar de mais recentes, são as que têm reagido com maior atraso diante desse desafio. Seja apelando para a ideia de globalização, seja incorporando a tese das modernidades múltiplas (CASANOVA, 2011), seus partidários, além de reiterarem a necessidade de ampliar o escopo empírico das análises, limitam-se a apregoar a necessidade de renovação teórica, sugerindo não mais que vagas pistas nesta direção.

No campo da versão ortodoxa da secularização, já conhecemos a alegação de que a perda de relevância da religião deve ser concebida como um fenômeno multidimensional, o que permitiria tratar o fenômeno de forma particularizada, com especial atenção para os diferentes espaços sociais em que ele se manifesta. Os ortodoxos também alegam que são os únicos a levar em conta as variaçóes históricas do processo de secularização. Ciente disso, Gert Pickel (2011) propóe um modelo que denomina de sensível ao contexto. Seguindo esta pista, estudos comparativos buscam identificar semelhanças e diferenças entre contextos históricos na tentativa de isolar os fatores que favorecem ou obstaculizam a secularização (HALIKIOPOULOU, 2012).

Dentre os estudos empíricos que se destacam, Demerath (2007), por exemplo, propóe-se a entender as diferentes dinâmicas da secularização levando em consideração o contexto político (imperialismo, colonialismo e descolonização), distinguindo ainda entre fatores internos e externos ao processo. Outro trabalho referencial, em se tratando de padróes de secularização, vem sendo desenvolvido por David Martin, cuja trajetória, por sinal, é marcada por fortes oscilaçóes. De crítico (MARTIN, 1965), ele passou a advogar uma teoria geral da secularização (MARTIN, 1978) para, ao final, voltar a relativizar essa abordagem (MARTIN, 2005). Esse trajeto também é marcado pela busca de incorporar novos casos empíricos ao seu estudo, contemplando a América Latina e a África (MARTIN, 2002) e, mais recentemente, os países do leste europeu (MARTIN, 2006). Para ele, a variedade dos processos de secularização está condicionada por dois fatores. O primeiro é de ordem política e diz respeito aos diferentes tipos de relação entre religião e política, aspecto 
que pode favorecer ou dificultar a dinâmica da secularização. Além dos fatores políticos, Martin também considera a importância dos elementos religiosos em si mesmos, investigando o papel da constelação histórico-confessional de determinada região ou país. A partir destes dois conjuntos de fatores, ele fornece uma descrição tipológica de diferentes modelos de secularização, que são: latino, americano, escandinavo, estatista de direita e estatista de esquerda. No entanto, se examinamos sua tipologia com mais cuidado, veremos que, na prática, se resume a três grandes constelaçóes: a católica, a protestante e a comunista (entendida como religiáo política).

O trabalho de Martin é ilustrativo quanto ao que estamos chamando aqui de múltiplas vias da secularização. O que este enfoque considera variável é 1) o ponto de partida histórico (religioso e político), 2) o modus operandi e o 3) ponto de chegada (que permanece indeterminado, a depender dos fatores em jogo) do processo de secularização. A multiplicidade é entendida como possiblidade de variação em cada uma dessas dimensôes, mas a definição do que possa ser a secularização em si mesma permanece uniforme. $\mathrm{O}$ modelo enfatiza somente a diferença entre os caminhos (vias) ou dinâmicas que nos conduzem, apesar de tudo, a um único e mesmo resultado, cuja variação, no máximo, é entendida como mais ou menos intenso ou bem-sucedido.

\subsection{Múltiplos secularismos}

Se, ao consideramos a multiplicidade de vias históricas mediante as quais se desenrola processo de secularização, ainda estamos nos movendo no interior do paradigma ortodoxo, ao falarmos de "múltiplos secularismos" já estamos em um ambiente epistemológico completamente diferente. A elevação do conceito de secularismo ao centro do debate contemporâneo nas ciências sociais deve-se principalmente aos trabalhos de Talal Asad, autor que desenvolve uma antropologia da religiáo (ASAD, 1993) assumindo pressupostos retirados do construtivismo nietszchiano/foucaultiano (ASAD, 2003, p. 16). Combinando o enfoque genealógico e a teoria da governamentalidade, Asad tornou-se um dos autores mais discutidos no campo dos estudos sociais da religião contemporânea.

$\mathrm{Na}$ constelação conceitual proposta pelo antropólogo, três são os termos chave (secularismo, secular e religioso), mas a relação entre eles não é simétrica: 
de um lado temos a díade religião/secular, oposição que é resultado de uma doutrina política ou ideologia - o secularismo - que postula a separação entre instituições políticas (razão pública) e religião (razão privada). Observe-se que o "secular" é o objeto a ser explicado (efeito), operação que nos remete ao "secularismo" como sua causa. Divergindo das clássicas teorias da secularização, Asad não centra sua análise na categoria "religião", considerada por uma ele uma construçáo moderna que nada tem de universal, mas no termo secular, definido como uma categoria epistêmica. Fundamental no procedimento genealógico de Asad é mostrar que a dissociação secular/religioso é resultado de um terceiro fator. Esse sujeito oculto é desvelado por meio do procedimento desconstrutivo.

Essa opção tem consequências diretas para as análises histórico-empíricas do autor que, servindo-se da teoria da governamentalidade, têm por escopo mostrar como foi engendrada, no Ocidente, essa construção discursiva. Opondo-se ao otimismo liberal, Asad sustenta que distinção secular/religioso está ligada ao surgimento do Estado Nação e à necessidade de pacificar os conflitos religiosos: trata-se, portanto, de um dispositivo disciplinar (mecanismo de controle) pela qual o poder soberano se impóe. A ideia de Europa (identidade), por sua vez, é fruto da construção do islamismo como o outro oposto à civilização (diferença).

Apesar de incorporar elementos dos estudos pós-coloniais e propor um olhar descentrado sobre o tema do secularismo (e do islamismo), o trabalho de Asad é criticado justamente pela ausência de trabalhos empíricos realizados fora dos limites do Ocidente (BANGSTAD, 2009). Mas, isso não impediu que, a partir dos impulsos fornecidos pelo seu trabalho, surgisse uma série de estudos buscando mostrar como, em diferentes contextos históricos, as fronteiras entre secular/religioso foram sendo definidas discursivamente (politicamente). Não é meu propósito aqui resenhar essas pesquisas, mas chamar a atenção para o fato de que elas trouxeram à baila a possibilidade de esquadrinhar múltiplos secularismos (WARNER, 2010), levando em consideração casos como o da Turquia (BOROVALI; BOYRAZ, 2014) e, especialmente, o da Índia (JAHANBEGLOO, 2011). Nesse ponto, os trabalhos antropológicos estão na dianteira da sociologia.

Em Asad não é apenas o termo secularização que não encontra espaço: o tema, em si mesmo, é completamente dissolvido. A transição processual de 
uma realidade de predomínio do religioso para um mundo secular é considerada um pseudoproblema, pois essa díade, como percebemos, nada mais seria do que reflexo do discurso político. Assim, embora o enfoque dos múltiplos secularismos amplie nossas possibilidades de pensar o registro das relaçóes entre religião e política para além do conceito de laicidade (a versão francesa do secularismo), conceito este excessivamente centrado na dimensão jurídica de regulação do religioso (PORTIER, 2011), o resultado é o estreitamento da problemática sociológica da secularização na direçáo do político. Como produto final, a teoria dos múltiplos secularismos nos fornece apenas mais uma sociologia política do Estado laico/secular como fruto de uma construção político-discursiva.

\subsection{Múltiplas secularidades}

Para fugir tanto da ortodoxia paralisante do modelo padráo, quanto do reducionismo político-construtivista da teoria da governamentalidade, alguns analistas têm buscado inspiração no modelo das variaçóes da modernidade de Shmuel Eisenstadt (2001).

A começar pela sociologia cultural das modernidades seculares proposta por Monika Wohlrab-Sahr e Marian Burchardt (2012), cujo objetivo consiste em absorver a discussão sobre secularidades no contexto da teoria das modernidades múltiplas. Com essa meta em mente, essas autoras introduzem um novo conceito no debate. Para elas, o termo secularismo fica reservado (como já em Asad) apenas para a construção ideológica, enquanto a secularidade (seu conceito central) é definida como o conjunto de significados culturais que determina a diferença entre espaços religiosos e não religiosos. $\mathrm{O}$ que as autoras desejam, portanto, é explicar a ancoragem cultural pela qual são construídos os arranjos que produzem a diferenciação entre a religião e as demais esferas da sociedade. Na visão de Wohlrab-Sahr e de Burchardt (2012), o conceito de secularidade seria mais amplo que o de secularismo, pois vai além da relação Estado/sociedade para voltar à relação clássica entre religião e as demais instâncias sociais, ou seja, ao binômio religião/sociedade. Ao mesmo tempo, o modelo preserva de Asad o pressuposto de que tais arranjos são fruto de conflitos políticos. Ademais, essas autoras explicam que a secularidade inclui o aspecto da diferenciação social, diluindo o construtivismo discursivo de matiz foucaltiana. Portanto, com Wohlrab-Sahr e Burchardt (2012), a temática 
do secularismo é reconectada com o domínio social, reabilitando o lugar das esferas sociais na análise sociológica.

A partir dessas premissas teóricas, as autoras propóem uma tipologia das formas de secularidade que leva em consideração contextos políticos que estariam confrontados com os seguintes problemas: como conciliar (1) liberdade ou unidade social, (2) o grau de heterogeneidade religiosa e seus potenciais conflitivos, (3) integração social/cultural com desenvolvimento ou (4) como garantir a independência política? É a depender das soluçóes dadas a estes quatro dilemas que podemos identificar quatro padróes de secularidade: (1) secularidade como garantia dos direitos e das liberdades individuais, (2), secularidade como balanceamento e pacificação da diversidade religiosa, (3) secularidade como busca da integração social ou nacional e sua compatibilizaçáo com o desenvolvimento e, (4) secularidade como busca do desenvolvimento autônomo de esferas sociais específicas (WOHLRAB-SAHR; BURCHARDT, 2012).

Ao introduzir as categorias institucionais e as práticas sociais em seu modelo, Wohlrab-Sahr e Burchardt (2012) não apenas evitam o reducionismo discursivo, mas também reconduzem o tema da secularidade/laicidade ao seio da sociologia. Fundamental é o fato de que a diferenciação social, um dos eixos da ideia weberiana de secularização, volta a ocupar o lugar analítico principal. Menos casuística, a tipologia proposta por ela também oferece elementos que nos permitem realizar análises comparativas, (generalização), evitando a mera descrição de contextos particulares (ideografia). Porém, mesmo descentrando o lugar do Estado e recuperando o papel das esferas sociais em sua análise, a proposta das múltiplas secularidades não escapa do reducionismo político que tem marcado a atual discussão sobre a relação religiấo e modernidade. Ainda que inovadora, sua tipologia também é, ao fim e ao cabo, uma sociologia política da secularidade/laicidade, e não uma ampla teoria sociológica da secularização.

Também para Schwinn (2003) a proposta da multiplicidade da modernidade é a referência central, mas ele prefere levá-la em direção diferente daquela encontrada em Shmuel Einsenstad, cuja leitura estava centrada nas diferenças culturais (civilizaçóes). Colocando no centro de sua análise a teoria weberiana das esferas de valor, ordens sociais e poderes de vida, Schwinn privilegia 
a dimensão estrutural da modernidade: religião, economia, política, direito, erotismo, arte e ciência, entre outras, são esferas que se encontram em múltiplas combinaçóes, a depender do contexto histórico-geográfico analisado. Sáo essas combinaçóes que respondem pela variedade de cenários modernos.

Como analista social cuja preocupação central é desenvolver um paradigma de orientação weberiana, é preciso lembrar, contudo, que suas análises extrapolam o campo da sociologia da religião strictu sensu que ele critica abertamente por limitar o tema da secularização à questão da relevância/irrelevância da religião. Propugnando uma visão alternativa, ele entende que o aspecto central da teoria weberiana da secularização não é a hipótese da persistência ou não da crença, mas sua permanente tensão com as demais esferas autonomizadas da modernidade (princípio de unidade), tese que já encontramos em Wolfgang Schluchter (1988). Não se trata, pois, de uma escolha binária entre dois cenários (diferenciação/moderno x desdiferenciação/não moderno), mas de considerar as múltiplas possibilidades que, em diversos cenários sociais concretos (constelaçôes sociais), existem entre religião e as demais esferas do mundo social (princípio da diversidade). É a partir desta plataforma institucional que seria possível comparar as variedades regionais nas quais as fronteiras, combinaçóes e oposições entre a esfera da religião e as demais esferas sociais são moldadas. Portanto, sem deixar de ser uma sociologia do conflito, Schwinn (2003) consegue ir além do policitismo e do culturalismo que ainda encontramos no modelo de Wohlrab-Sahr e de Burchardt (2012), visto que restabelece a pluralidade (sem dominância) das lógicas sociais, sem aderir aos vínculos de uma teoria da modernização.

\section{Considerações finais}

Em Max Weber, o deslocamento da religião do centro para a periferia da ordem social é elemento constitutivo da condição moderna (princípio de unidade). Ao mesmo tempo, tal temática foi analisada por ele a partir de diversos ângulos, incluindo tanto a perspectiva histórica quanto a estrutural (princípio de diversidade). No campo da sociologia da religiáo, o debate em torno da relevância ou irrelevância da religião no mundo moderno representa uma importante linha de desenvolvimento da pesquisa de Weber, ainda que não a esgote completamente. No entanto, atualmente tal querela é censura- 
da por assumir inadvertidamente os pressupostos da teoria da modernização, acirrando ainda mais as críticas ao conceito. Defrontando-se com esta crítica, este artigo buscou desvincular a discussão sobre a secularização da dualidade tradição/modernidade para situá-la no horizonte da díade unidade/multiplicidade, proposta por Shmuel Eisenstadt, evitando, assim, a armadilha da convergência. A partir desse exercício, assim entendemos, abre-se a possibilidade de contemplar a(s) variedade(s) da secularização segundo registros plurais, incluindo suas variaçóes históricas, arranjos políticos, cenários culturais e configuraçôes socioinstitucionais. Lida dessa forma, a teoria da secularização de orientação weberiana apresenta-se, ainda, como um instrumento válido não só para a análise da pluralidade do religioso em condiçóes modernas mas também como recurso analítico relevante para determinar tanto os elementos de unidade quanto de multiplicidade da própria modernidade. Sociologia da religião e teoria social recuperam, assim, seu laço intrínseco.

Permanece como um desafio, contudo, determinar qual o núcleo duro do conceito weberiano de secularização sem incorrer em reducionismos que essencializam o histórico, o político, o cultural e o institucional. No presente momento, o global turn que impulsiona as ciências sociais vem acompanhado de um forte political turn, enfraquecendo um olhar sociológico multidimensional que se situe para além da alternativa do monismo ou da fragmentação. Neste contexto, a retomada do conceito de secularização precisa contemplar a variável laicidade ou secularismo como uma das suas dimensóes, mas sem deixar-se reduzir a elas. Da mesma forma, um conceito de secularização capaz de responder aos desafios da pluralização das experiências do moderno náo pode reduzir-se apenas ao elemento institucional (autonomia e conflito entre as esferas de valor), sem deixar de considerar a individualizaçáo crescente das práticas religiosas (no sentido positivo dado a noção por Charles Taylor). Preocupaçóes que uma releitura crítico/criativa da tese de secularização Weber pode nos ajudar a enfrentar.

\section{Referências}

ACQUAVIVA, S; STELLA, R.; BERZANO, L. Differenziazione e religion eneglianni Ottanta. Turim: Giappechelli, 1990.

ASAD, T. Genealogies of religion. Discipline and reasons of power in Christianity and Islam. Baltimore: Johns Hopkins University Press, 1993. 
Formations of the Secular: Christianity, Islam, Modernity. Stanford: Stanford University Press, 2003.

BANGSTAD, S;. Contesting secularism/s. Anthropological Theory. Vol 9, Issue 2, 2009, pp. $188-208$.

BELL, Daniel. The Return of the Sacred? British Journal of Sociology, v. 28, n. 4, p. 419449, dec. 1977.

BELLAH, R. The Broken Covenant: American Civil Religion in Time of Trial. New York: Seabury, 1975.

BERGER, P. The Sacred Canopy: Elements of a Sociological Theory of Religion. New York: Anchor Doubleday, 1967.

. The Desecularization of the World: A Global Overview. In: BERGER, E. The Desecularization of the World: Resurgent Religion and World Politics. Washington, D. C.: The Ethics and Public Policy Center/Grand Rapids, Mich; William B. Eerdmans, 1999.

BLUMENBERG, H. [1966]. Die Legitimität der Neuzeit. Frankfurt/M: Suhrkamp, 1996.

BOROVALI, M.; BOYRAZ, C. Turkish secularism and Islam: a difficult dialogue with the Alevis. Philosophy \& Social Criticism, v. 40, n. 4-5, p. 479-488, may/june 2014.

BORUTTA, M. Antikatholizismus: Deutschland und Italien im Zeitalter der europaischen Kulturkämpfe: Vandenhoeck \& Ruprecht, 2010.

BRUCE, S. Religion in the Modern World. Oxford: Oxford University Press, 1966.

A House Divided: Protestantism, Schism and Secularization. London: Routledge, 1990.

Religion and Modernization: Sociologists and Historians Debate the Secularization Thesis. Oxford: Clarendon Press, 1992.

The Death of God: Secularization in the West. Oxford: Blackwell, 2002.

.. God is Dead: Secularization in the West. Oxford: Blackwell, 2011 a.

. Secularization. In: Defence of an Unfashionable Theory. Oxford: Oxford University Press, 2011 b.

CARROLL, A. The Importance of Protestantism in Max Weber's Theory of Secularisation. European Journal of Sociology / v. 50, issue 1, p. 61-95, apr. 2009. 
CASANOVA, J. Public Religions in the Modern World. Chicago: University of Chicago Press, 1994.

- Secularization Revisited: A Reply to TalalAsad. In: DAVID SCOTT, D; HIRSCHKIND, C. (Ed.) Powers of the Secular Modern: Talal Asad and his Interlocutors. Stanford: Stanford University Press, 2006. p.12-30.

- Cosmopolitanism, the clash of civilizations and multiple modernities. Current Sociology, v. 59, n. 2, p. 252-267, 2011.

CHAVES, M. Secularization as Declining Religious Authority. Social Forces, v. 72, p. 749 $774,1994$.

CRISTIANO, K.; SWATOS, W. Secularisation Theory: The Course of a Concept. Sociology of Religion, v. 60, n. 3, p. 2009, 1999.

DAVIE, G. 1994. Religion in Britain Since 1945: Believing Without Belonging. Oxford: Blackwell, 1994.

Europe: The Exceptional Case: Parameters of Faith in the Modern World. London: Darton, Longman and Todd, 2002.

DEMERATH, N. J. Secularization and Sacralization. In: BECKFORD, J. A.; DEMERATH, N. J. The sage handbook of the sociology of religion. London: SAGE, 2007. p. 57-80.

DEMERATH III, J. N. Excepting Exceptionalism: American Religion. Comparative Relief. Annals of the American Academy of Political and Social Science, v. 558, p. 28-39, july 1998

DOBBELAEERE, K;. Secularization:an analysis at three levels.Bruxelles [u.a.]: PIE Lang, 2002.

DUTRA, R. A Universalidade da Condição Secular. Religiáo e Sociedade, Rio de Janeiro, v. 36, n. 1, p. 151-174, 2016.

EISENSTADT, S. N. Multiple modernities. Daedalus, v. 129, n. 1, p. 1-29, winter, 2001.

GANGULY, S. The Crisis of Indian Secularism. Journal of Democracy, v. 14, n. 4, p. 11-25, 2003.

GAUCHET, M. Le désenchantementdu monde. Une histoire politique de lareligion. Paris: Gallimard, 1985.

GORSKI, P. Historicizing the Secularization Debate: Church, State, and Society in Late Medieval and Early Modern Europe. American Sociological Review, v. 65, p. 138-167, 2000. 
Historizing the secularisationdebage: An agenda for research. In: DILLON, M.

(Org.). Handbook of the sociology of Religion. Cambridge, 2003. p. 110-122.

GRAF, F. W. Die Wiederkehr der Götter: Religion in der modernen Kultur. München: Beck, 2004 .

HABERMAS, J. Entre naturalismo e religiáo: estudos filosóficos. Rio de Janeiro: Tempo Brasileiro, 2007.

HADDEN, J. K. Toward desacralizing secularization theory. Social Forces, v. 65, n. 3, p. 587-611, 1987.

HALIKIOPOUlOU, D. Patterns of Secularization: Church, State and Nation in Greece and the Republic of Ireland. Contemporary Sociology: A Journal of Reviews, v. 41, n. 3, p. 385-385, 2012.

HÉRVIEU-LÉGER, D. Versun nouveau christianisme? Introduction à la sociologie du christianisme occidental. Paris: Latour-Marbourg, 1986.

La religion pour memoire. Paris: Cerf, 1993.

Le pèlerin et le converti: la religion en mouvement. Paris: Flammarion, 1999.

HUGHEI, M. The Idea of Secularisation in the Works of Max Weber: a Theoretical Outline. Qualitative Sociology,

NORRIS, P.; INGLEHART, R. Sacred and Secular: Religion and Politics Worldwide. New York: Cambridge University Press, 2004.

JAHANBEglOO, R.. Two concepts of secularism. Comparative Studies of South Asia, Africa and the Middle East, Volume 31, Number 1, 2001, p. 13-22.

JELLINECK, G. Die Erklärung der Menschen- und Bürgerrechte. Schnur, Roman (Hg.). Zur Geschichte der Erklärung der Menschenrechte. Darmstadt: Wissenschaftliche Buchgesellschaft, 1895.

JOAS, H. Glaube als Option. Freiburg: Herder, 2012.

KEPEL, G. La revanche de Dieu: chrétiens, juifsetmusmulmans à lareconquêtedu monde. Paris: Seuil, 1991.

KOSCHORKE, A. Säkularisierung und Wiederkehr der Religion: zu zwei Narrativen der europäischen Moderne. In: WILLEMS, U.; POLLACK, D.;; BASU, H., GUTMAN, Thomas. Moderne und Religion: Kontroversen um Modernität und Säkularisierung. Bielefeld: Transcript-Verl., 2013. p. 237-260. 
LEHMANN, H. Säkularisierung. Der europäische Sonderweg in Sache Religion. Göttingenn: Wallstein-Verlag, 2004.

LÖWITH, K. Weltegeschichte und Heilsgeschehen. Die theologischen Voraussezungen der Geschitsphilosophie, 1949.

LÜBBE, H. Säkularisierung: Geschichte eines ideenpolitischen Begriffs. Freiburg; München: Karl Alber, 1965.

LUCKMANN, T. The Invisible Religion: the Transformation of Symbols in Industrial Society. London: CollierMacmillan, 1967.

LUHMANN, N. Die Religion der Gesellschaft. Frankfurt: Suhrkampf, 2002.

MARIANO, R. Sociologia da religiâo e seu foco na secularização. In: PASSOS, J. D.; USARSKI, F. (Org.). Compêndio de ciência da religiáo. São Paulo: Paulinas, 2013. p. 231-242.

MARRAMAO, G. Die Säkularisierung der westlichen Welt. Frankfurt a. M: Insel Verlag,, 1999.

MARTELLI, S. A religião na sociedade pós-moderna: entre secularização e dessecularização. São Paulo: Paulinas, 1995.

MARTIN, D. Towards eliminating the concept of secularisation. In: Penguin survey of the social sciences, edited by J. Gould, 169-82. Baltimore, MD: Penguin, 1965.

A General Theory of Secularization. Oxford: Blackwell, 1978.

. Tongues of Fire: the Explosion of Protestantism in Latin America. Oxford: Blackwell, 1990.

Pentecostalism: The World Their Parish. Oxford: Blackwell, 2002.

. On Secularization: Toward a Revised General Theory. Burlington, Vt.: Ashgate, 2005 .

Comparative secularisation Norh and South. In: FRANZMAN, M.; GÄRTNER, C., KÖCK, N. (Org.). Religiosität in der säkularisierten Welt. VS Verlag: Göttingen, 2006. p. 105-122.

MONOD, J-C. La querelle de la sécularization: de Hegel à Blumenberg. Paris: Vrin, 2002. MONTERO, P. Religióes e dilemas da sociedade brasileira. In: O que ler na ciência social brasileira (1970-1995). São Paulo: ANPOCS, 1999, v. 2. p. 327-367. 
. Max Weber e os dilemas da secularização: o lugar da religião no mundo contemporâneo. Novos Estudos do Cebrap, São Paulo, n. 56, p. 35-45, 2003 a.

. Max Weber e os dilemas da secularização. Novos Estudos do Cebrap, São Paulo, n. 65 , p. 34-44, mar. 2003b.

Controvérsias religiosas e Esfera Pública: repensando as religióes como discurso. Religiáo \& Sociedade (Impresso), v. 32, p. 15-30-30, 2012.

MOUZELIS, N. Modernity and the Secularization Debate. Sociology, v. 46, n. 2, p. 207-223, 2012.

NEGRÃO, L. N. Nem "jardim encantado", nem "clube dos intelectuais desencantados". Revista Brasileira de Ciências Sociais, v. 20, n. 59, p.25-36, 2005.

NORRIS, P.; INGLEHART, R. Sacred and Secular: Religion and Politics Worldwide. Cambridge: Cambridge University Press, 2004.

ORTIZ, R. Mundialização: saberes e crenças. São Paulo: Brasiliense, 2006.

PICKEL, G. Säkularisierung, Individualisierung oder Marktmodell?. Kölner Zeitschrift für Soziologie, June 2010, Volume 62, Issue 2, pp 219-245.

PIERUCCI, A. F. A propósito do auto-engano em sociologia da religião. Novos Estudos do Cebrap, n. 49, p. 99-118, 1997 b.

Interesses religiosos dos sociólogos da religião. In: ORO, A.; STEIL, C. A. (Org.).

Globalizaçáo e religiáo. Petrópolis: Vozes, 1997a. p. 249-262.

Secularização em Max Weber: da contemporânea serventia de voltarmos a acessar aquele velho sentido. Revista brasileira de ciências sociais, n. 37, p. 43-73, 1998.

Sociologia da Religião: área impuramente acadêmica. In: O que ler na ciência social brasileira (1970-1995). São Paulo: ANPOCS, 1999, v. 1. p. 237-286.

O desencantamento do mundo: todos os passos do conceito em Max Weber. São Paulo: ed. 34, 2003.

POLLACK, D. Säkularisierung: ein moderner Mythos? Tübingen: Mohr Siebeck, 2012. .; MÜllER, O.; PICKEL, G. (Org.). The Social Significance of in the Enlarged Europe: Secularization, Individualization and Pluralization. Aldershot: Ashgate, 2012.

POMPA, C. Introdução ao Dossiê Religião e Espaço Público: repensando conceitos e contextos. Religiáo e Sociedade, v. 32, n. 1, p. 157-166, 2012. 
PORTIER, P. A regulação estatal da crença nos países da Europa Ocidental. Religiáo \& Sociedade, v. 31, n. 2, p. 11-28, 2011.

RIESEBRODT, M. Die Rüccker der Religionen. Fundamentalismus und der 'Kampf der Kulturen'. München, 2000.

.Religiöse Vergemeinschaftungen. KIPPENBERG, H. G.; (Org.). Meine, Religionsystematik.Tübingen: MohrSiebeck, 2001. p. 101-119.

SCHLUCHTER, W. Die Zukunft einer Religion. Religion und Lebensführung. Suhrkamp: Frankfurt am Main, 1988, v. II. p. 506-534.

SCHWINN, T. Zur Neubestimmung des Verhältnisses von Religion und Moderne. Säkularisierung, Differenzierung und multiplen Modernitäten. Kölner Zeitschrift für Soziologie und Sozialpsychologie, n. 53, p.73-98, 2013.

SELL, C. E. Max Weber e a racionalização da Vida. Petrópolis: Vozes, 2013.

Weber no Século XXI: Desafios e Dilemas de um Paradigma Weberiano. Dados, v. 57 , n. 1 , p. $35-71,2014$.

. A secularização como sociologia do moderno: Max Weber, a religião e o Brasil no contexto global. Revista Brasileira de Ciências Sociais, v. 3, n. 6, p. 11-46, 2015.

SHINER, L. The concept of secularization in empirical research. Journal for the Scientific Study of Religion, v. 6, p. 207-220, 1967.

SPOHN, U. (Org.). Moderne und Religion: kontroversen um Modernität und Säkularisierungg. Bielefeld, 2013.

STARK, R. Secularization, R.I.P. Sociology of Religion, v. 60, n. 3, p. 249-273, 1999.

TAVOLARO, S. B. F. Existe uma Modernidade Brasileira? Reflexôes em torno de um dilema sociológico brasileiro. Revista Brasileira de Ciências Sociais, v. 20, n. 59, p. 5-22, 2005.

TAYLOR, C. A Secular Age. Cambridge: Harvard University Press, 2007.

TEIXEIRA; F.; MENEZES, R. (Org.). As religióes no Brasil: continuidades e rupturas. Petrópolis: Vozes, 2006. .; ___ (Org.). Religióes em Movimento. Petrópolis: Vozes, 2013.

TORPEY, J. A Post Secular Age? Religion and the Two Excepcionalisms. Social Research, v. 77, n. 1, 2010, p. 269-296, 2010. 
TSCHANNEN, O. The Secularization Paradigm: A Systematization. Journal for the Scientific Study of Religion, v. 30, p. 395-415, 1991.

VELHO, O. O que a Religião pode fazer pelas Ciências Sociais? Religiáo \& Sociedade, Rio de Janeiro, v. 19, n. 1, p. 9-17, 1998.

WALLIS, R.; BRUCE, S. Secularization: The Orthodox Model. In: BRUCE, S. (Ed.). Religion and Modernization: Sociologists and Historians Debate the Secularization Thesis. Oxford: Oxford University Press, 1992. p. 8-30.

WARNER, M. et al. (Ed.). Varieties of Secularism in a Secular Age. Cambridge: Harvard University Press, 2010..

WEBER, M. Die protestantischen Sekten und der Geist des Kapitalismus. In:

Gesammelte Aufsätze zur Religionsoziologie. Tübingen: Mohr Siebeck, 1988. 207-236.

. Zwischenbetrachtung. Die Wirtschaftsethik der Weltreligionen. Konfuzianismus und Puritanismus (Schriften 1915-1920). In: SCHMIDT-GLINZER, H.; KOLONKO, P. (Org.). Tübingen: Mohr Siebeck, 1989. p. 479-522.

WEISS, R. O Sagrado e a Moralidade Laica na Teoria Moral Durkheimiana. Revista Pós Ciências Sociais, v. 10, p. 47-68, 2013.

WILSON, B. Religion in Secular Society. London: Watts, 1966.

Religion in Sociological Perspective. Oxford: Oxford University Press, 1982. . Secularization. In: HAMMOND, P. E. (Ed.). The sacred in a secular age. Berkeley: University of California Press, 1985. p. 1-20.

WOHLRAB-SAHR, M.; BUCHARDT, M. Multiples secularities: Toward a cultural sociology of secular modernities. Comparative Sociology, v. 11, p. 875-909, 2012.

YAMANE, D. Secularization on Trial: In Defense of a Neo-Secularization Paradigm. Journal for the Scientific Study of Religion, v. 36, p. 109-122, 1997.

ZEPEDA, J. de J. Secularização ou ressacralização? O debate sociológico contemporâneo sobre a teoria da secularização. Revista Brasileira de Ciências Sociais, v. 25, n. 73, p. 129-141, 2010. 


\section{Multiple secularizations: The sociology of religion in the globalization era}

\section{Abstract}

The weberian theorem of secularization it is currently criticized for reproducing assumptions coming from modernization theories that suppose an unilinear transition from the tradicional to modern. Based on the idea of unity and variation developed by Shmuel Einsenstadt, this article discusses the possibilities of updating the concept faced with a backdrop of globalization and the multiplicity of modernity. After demonstrating that in Max Weber the subject is already treated in a multidimensional way, it revises up the debate on secularization in the sociology of religion. In the final part, it critically discusses three different ways of updating the theme of secularization: a) multiplicity of pathways of secularization, b) multiple secularisms c) multiple secularities. Focusing on macrosociologic theories, the general purpose of the text is to integrate the concept of secularization in the discussion of the nature and diversity of modernity in present times.

Keywords: Max Weber. Multiple Modernities. Secularization. Religion. Social Differentiation.

Recebido em: 22/11/2016. Aprovado em: 28/03/2017. 